\title{
Preview Brief 2: Wildland Fire Management under COVID-19, Survey Results
}

\author{
Cathelijne R. Stoof ${ }^{1}$, Jasper R. de Vries ${ }^{2}$, P. Marijn Poortvliet ${ }^{2}$, Bethany Hannah ${ }^{3}$, Ron Steffens ${ }^{4}$, Peter \\ Moore $^{5}$
}

${ }^{1}$ Department of Environmental Sciences, Wageningen University, The Netherlands

${ }^{2}$ Strategic Communication Group, Wageningen University, The Netherlands

${ }^{3}$ The American Wildfire Experience, USA

${ }^{4}$ Wildfire Magazine, International Association of Wildland Fire; Prescott College, USA

${ }^{5}$ Food and Agriculture Organization of the United Nations, Rome, Italy

\section{Executive summary}

Wildland fire management is impacted by COVID-19 as a result of strict hygiene and social distancing requirements. Here, we give a preview of the of our online survey (link) that aimed to clarify implications of COVID-19 restrictions on wildland fire management, map current thinking, and collate any plans, protocols or procedures to generate generic guidance for wildland fire professionals. The survey was completed by 443 individuals from over 38 countries, working at a large variety of organizations in terms of organization type, level of jurisdiction, primary function, and the size of the fire management and fire suppression work force. This preview includes the most important preliminary results. In short, the data indicates that people are worried about the effect of COVID-19 on wildland fire management and also expect this to impede management. Despite this, there is high confidence that operations can be continued during the pandemic. COVID-19 hygiene and distancing requirements are being widely adopted, which is being reflected by a reduced number of staff per vehicle. There is an expected reduction in support services being available. Notable to mention is furthermore the expected reduction in sharing and receiving of resources (from and to other countries, regions) in times of need. Finally, training and risk reduction activities are also impacted, suggesting a longer-term impact of the pandemic on fire management. Two main concerns highlighted by survey respondents are the lack of preventive COVID-19 testing amongst wildland fire fighters, and the increased risk of vehicle accidents if staff is spread across more vehicles. We are now analyzing the wealth of responses including over 30.000 words of comments shared, and plan to publish the full analysis mid June.

Please cite this preview as: Stoof, C.R., De Vries, J.R., Poortvliet, P.M., Hanna, B., Steffens, R. Moore, P. (2020). Preview Brief 2: Wildland Fire Management under COVID-19, Survey Results. Wageningen University, The Netherlands https://doi.org/10.18174/522586.

The full report of Brief 2 will be available at https://doi.org/10.18174/521465.

Corresponding authors: Peter.Moore@fao.org; Cathelijne.Stoof@wur.nl

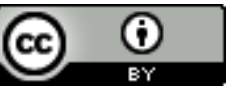

This work is licensed under a Creative Commons Attribution 4.0 International License. This allows the user to redistribute, to create derivatives, such as a translation, and even use the publication for commercial activities, provided that appropriate credit is given to the author (BY) and that the user indicates whether the publication has been changed. For the license terms, see here.

Translators sought: We are looking for people who would like to translate our Briefs so we can communicate this material to a wider public. If you are interested in translating (any language is welcome) please contact the corresponding authors for a Word version of this report. 


\section{Table of Contents}

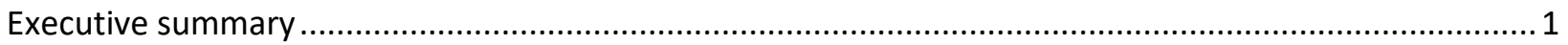

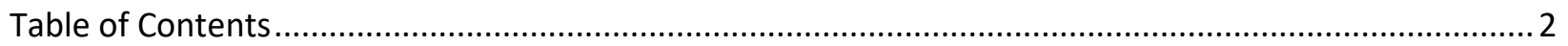

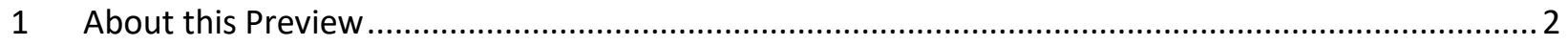

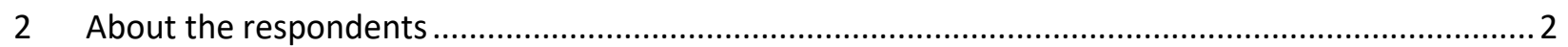

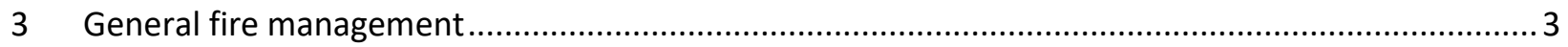

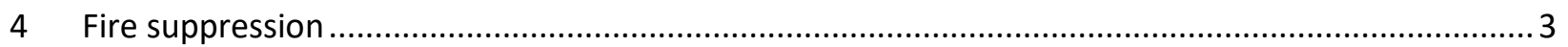

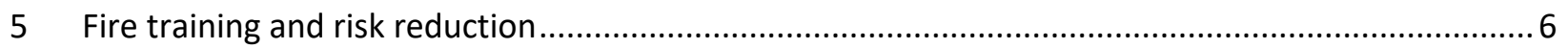

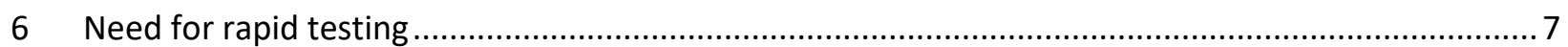

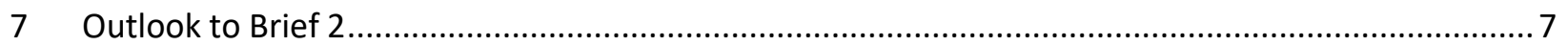

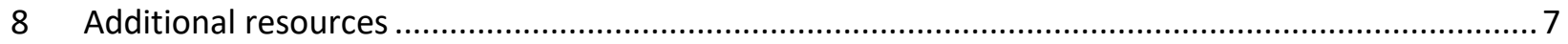

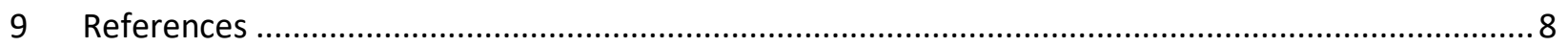

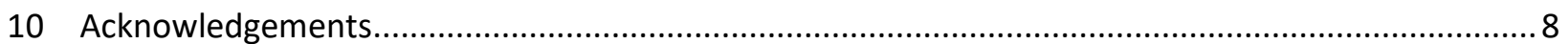

\section{About this Preview}

This preview is intended to rapidly release the most important insights from the online survey Wildland Fire Management under COVID-19 which was circulated in the wildland fire community in April and May 2020. The goal of the survey was to compile materials, clarify the implications of COVID-19 restrictions on wildland fire management, map current thinking and raise awareness of this issue. This is a preview of Brief 2 that presents all survey results, a second in a series that started with a review of wildland fire \& COVID-19 guidance materials, which was published early May 2020 (Moore et al, 2020).

Since this is a rapidly produced preview, results shared here are preliminary. Details may still change because questions that contained 'other, please specify' categories have for instance not been collated with the answers presented here. We share these first preliminary results to allow for rapid learning during this pandemic. For the final numbers and analysis, please refer to our Brief 2 that will be published here mid June 2020.

\section{About the respondents}

The survey was completed by 443 individuals from over 38 countries (Fig. 1). All continents are represented, and with several temperate countries the origin of the respondents extends beyond the 'typical' fire countries. Roughly $40 \%$ of respondents are based in the USA, high above any other country. Spain, Italy, South Africa, Australia, Canada and Portugal make up the next 20\% (and another 20\% did not fill out this question).

The majority of respondents are active in wildland fire management, a smaller proportion is active in both wildland fire and structural fire management. Total staff sizes of organizations represented in the survey range from 1-10 to $>500$, with also a large spread in the number of fire management and fire suppression staff. Most respondents work for government organizations. Level of jurisdictions range from province/state to national, local and international, in order of decreasing frequency. Seven respondents work for tribal agencies. Fire management and landscape management are the primary and secondary functions that have been listed most, with emergency services ranking in third place. 


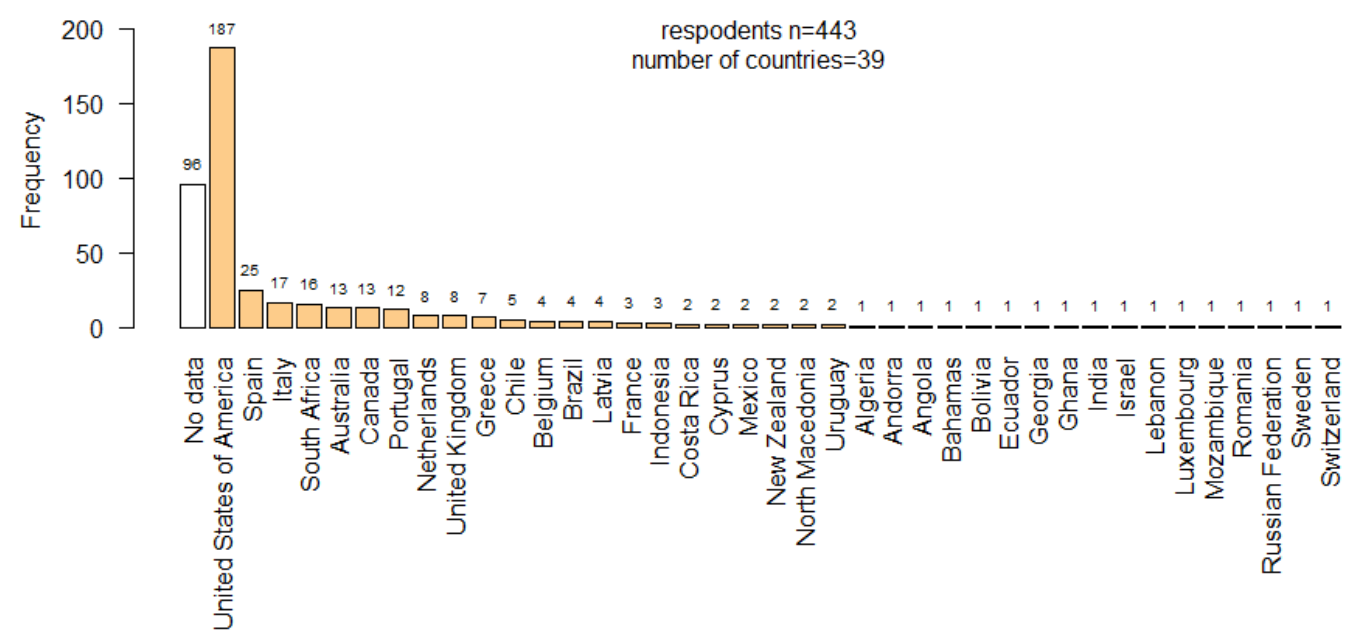

Figure 1 Preliminary overview of the country of survey respondents

\section{General fire management}

The data shows that there is a lot of concern over the impact of COVID-19 on the operation of the respondents' organizations, and that COVID-19 is expected to considerably impact fire management (Fig. 2 ). In addition, results from the open questions show a great deal of uncertainty about the impact of the COVID-19 measures in the future, as fire seasons have not started or measures are subject to constant change. Despite this, there is high confidence that fire management tasks can be performed during this pandemic by the represented organizations (Fig. 2).
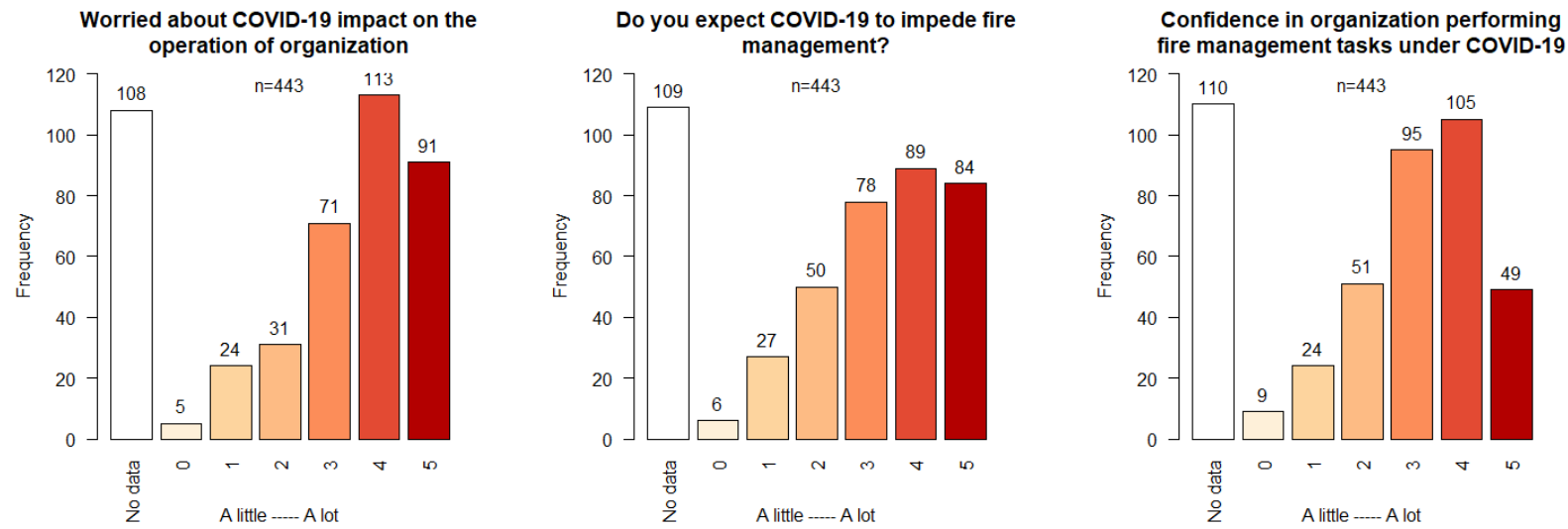

Figure 2 Perception of COVID-19 effects on general fire management (preliminary). Here, $n$ indicates the number of respondents.

\section{Fire suppression}

It is clear that COVID-19 requirements are being widely adopted among the respondents' organizations. Of the 310 people who answered this question, the far majority has adopted social separation measures, followed closely by hygiene measures, disinfection and cleaning, and control of group size (Fig. 3). The data also show that COVID-19 is expected to reduce the availability of support services (e.g. logistics and supply, catering, aviation maintenance and supply, accommodation, transportation), followed by other services, and to a small degree that of specialist services (e.g. meteorology, air quality, remote sensing); Fig. 3b). 
COVID-19 requirements adopted

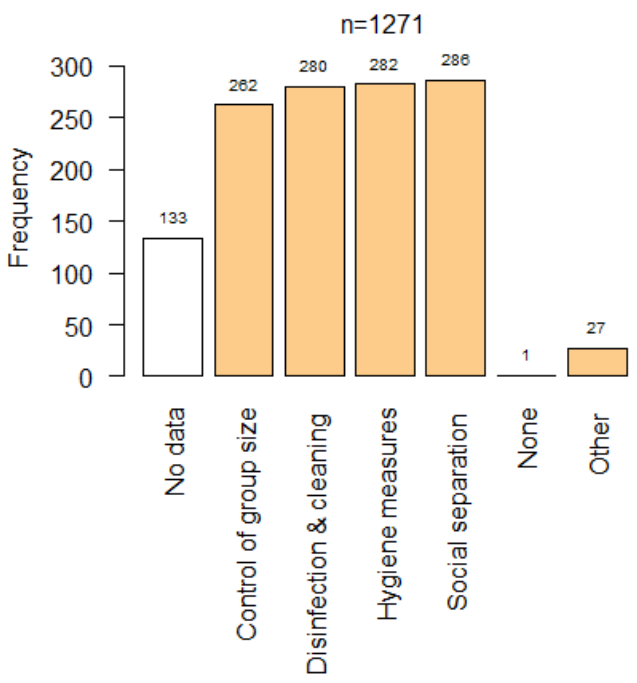

Type of services reduced

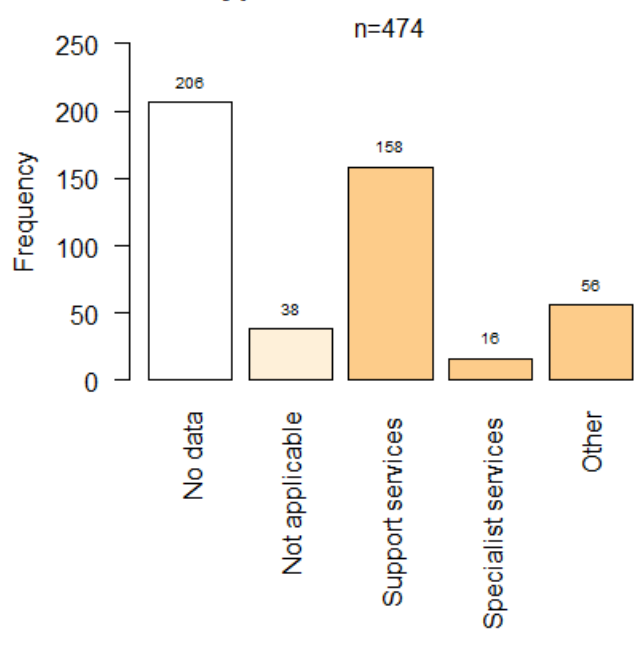

Figure 3 COVID-19 requirements and type of services reduced (preliminary). Here, $n$ indicates the number of answers (respondents were allowed to select all that applied), not the number of respondents.

Fire can spread through the landscape regardless of administrative boundaries and sharing of resources across these boundaries is routine, be it between continents, countries, provinces/states, or municipalities/counties. As a result of COVID-19, respondents report a reduction in their ability to share resources and services with others in need (Fig. 4), and likewise an impact on the opportunity to receive help from other regions or countries if in need (Fig. 4). With COVID-19 requirements being focused on social distancing and limiting the exchange between groups and regions, a reduction in sharing of personnel and aviation resources is not surprising but may prove to be a major challenge in case of extreme or otherwise challenging wildfires.
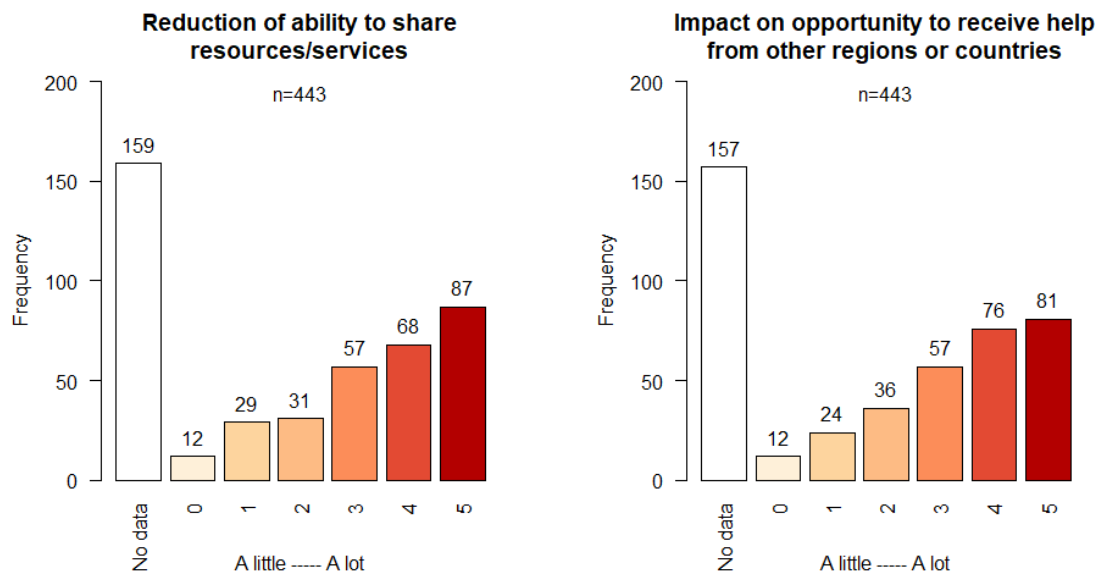

Figure 4 Effect of COVID on sharing and expected receiving of resources if in need (preliminary). Here, $n$ indicates the number of respondents. 
To facilitate sharing and receiving of resources during this pandemic, simple checklists are being developed such as the one shown in Fig. 5 that was developed by the National Multi-Agency Coordinating Group.

\begin{tabular}{|c|c|c|c|}
\hline & & Yes & No \\
\hline 1 & Confirm Best Management Practices are in place to mitigate COVID-19. & & \\
\hline 2 & $\begin{array}{l}\text { Description of any additional supply/equipment needs (self-sufficient, } \\
\text { food, water, extended camping equipment, etc.) }\end{array}$ & & \\
\hline 3 & $\begin{array}{l}\text { There is a medical plan in place with identified care facilities for COVID- } \\
19 \text { patients. }\end{array}$ & & \\
\hline 4 & $\begin{array}{l}\text { Describe the level of COVID-19 outbreak in the county where the fire is } \\
\text { located from the following website: https://coronavirus.jhu.edu/us-map }\end{array}$ & & \\
\hline \multicolumn{4}{|c|}{ SENDING UNIT - Is the following met? } \\
\hline & & Yes & No \\
\hline 1 & $\begin{array}{l}\text { All individuals filling the order have been screened using the MPHAT } \\
\text { Wildland Fire Screening Tool or their employing agency's equivalent. }\end{array}$ & & \\
\hline 2 & $\begin{array}{l}\text { The resource is equipped with PPE and supplies required to adhere to } \\
\text { COVID- } 19 \text { mitigation protocols during mobilization and for at least three } \\
\text { operational periods. }\end{array}$ & & \\
\hline 3 & $\begin{array}{l}\text { The resource is prepared to be self-sufficient regarding food and water } \\
\text { for at least the first three operational periods if driving. }\end{array}$ & & \\
\hline 4 & $\begin{array}{l}\text { The resource can meet any additional supply/equipment needs } \\
\text { identified in the Special Instructions section of the resource order. }\end{array}$ & & \\
\hline 5 & $\begin{array}{l}\text { There is an isolation/quarantine plan in place to use upon return to the } \\
\text { home unit that can be implemented if deemed necessary. }\end{array}$ & & \\
\hline
\end{tabular}

Figure 5 Interagency Checklist for Mobilization of Resources in a COVID-19 Environment, developed by the National MultiAgency Coordinating Group (NMAC, source).

A final result we highlight here regarding fire suppression is the impact of COVID-19 on the number of staff per vehicle (Fig. 6). The data shows that in a large number of cases, the number of staff per vehicle is reduced as a result of COVID-19 requirements. Survey respondents highlight the challenges this causes, not only because there may not be enough space for increased vehicle numbers on the fireground (Fig. 6), but also because 'it's trading a possible risk [COVID-19] for a known risk (driving while exhausted), as 'driving is one of the most frequent killers in our business' (Fig. 6).

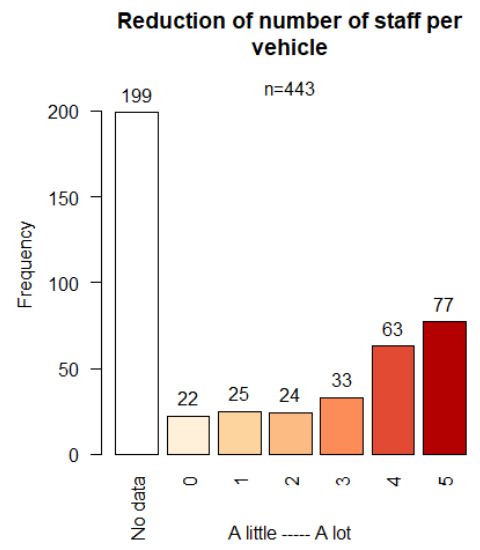

Having sufficient space for vehicles
* Another issue that's come up already, a lot of folks were urging to spread
folks out among more vehicles. I. e instead of six to a crew cab pickup, maybe
just $2-4$, and add more vehicles. There have already been after action reviews
come out on a couple fires where that created major issues, because so many
vehicles showed up they flilled their safety zones and helispots up and ran out
of space. Some tried to mitigate that by moving everyone back into shared
vehicles upon arrival, but that negates the value of having brought more.
Vehicle accidents
* The greatest killer of wildland firefighters is vehicle accidents. 20-person
crews adding an additional vehicle or two increases that exposure.
* And, it's trading a possible risk for a known risk [driving while exhausted].
We already know that driving is one of the most frequent killers in our
business, and exhausted driving (like after a 16 hour shift) is really bad.
That's a known risk.

Figure 6 COVID-19 effects on the number of staff per vehicle (preliminary; $n$ is the number of respondents), and example of survey comments on the reduced number of staff per vehicle. 


\section{Fire training and risk reduction}

Aside from the effects of COVID-19 on general fire management and fire suppression as discussed above, respondents indicate considerable effects on training, pre-season community engagement, fuel management, and other risk reduction activities (Fig. 7). From the open questions it is clear that the nature of these impacts is that in many instances these activities are canceled or reduced. It can be reasonably expected that the reduction in these activities can impact not only fire risk to communities but also the risk to those working on fire management. In addition, it shows the potential long term impact of COVID19 on fire management.
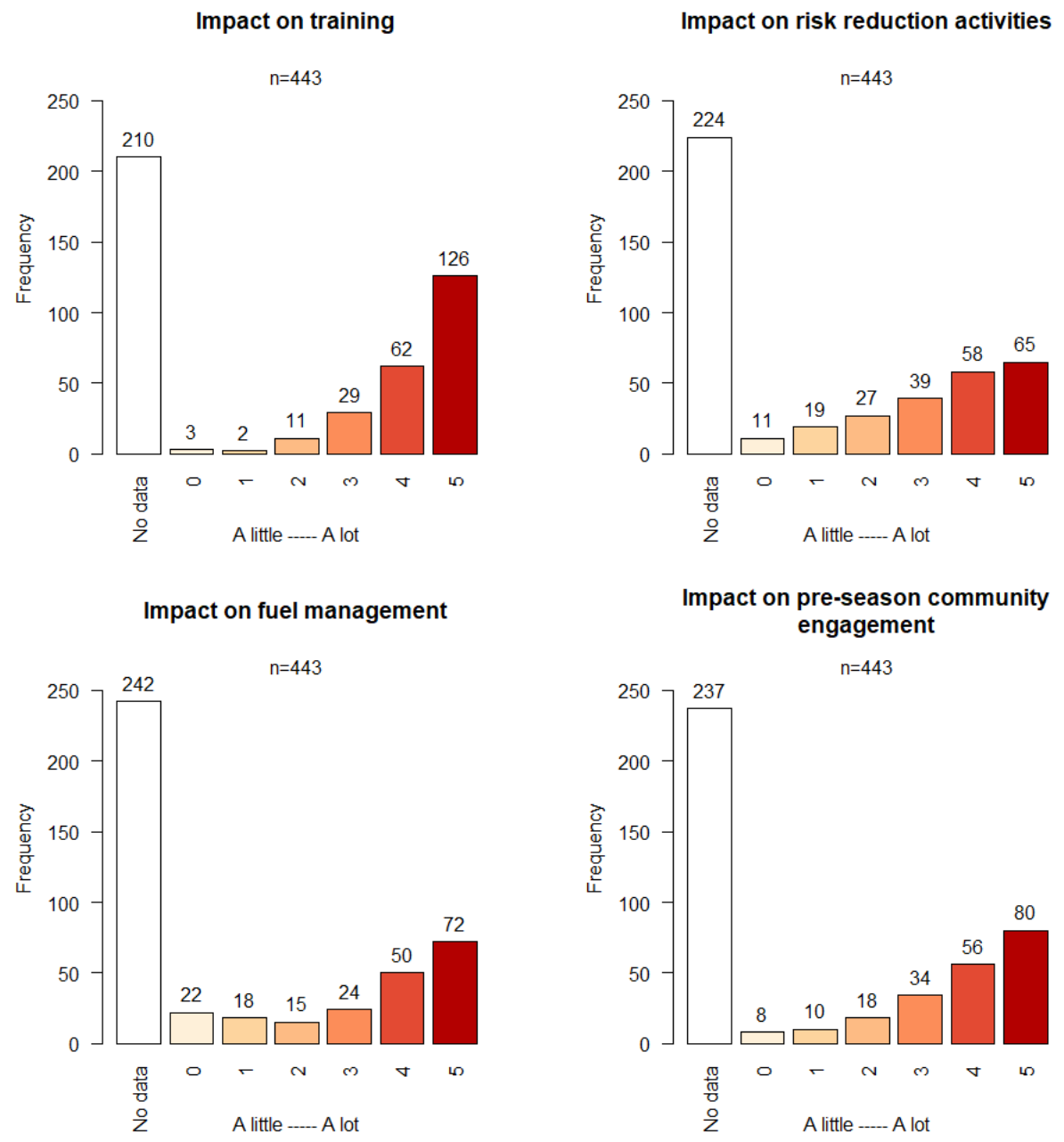

Figure 7 COVID-19 effects on fire training and risk reduction (preliminary). $N$ is the number of respondents. 


\section{Need for rapid testing}

One major current concern in the fire community is the lack of COVID-19 testing for wildland fire fighters.

To which degree this is an issue globally is yet unclear, but in the USA testing for COVID-19 is not available unless people show COVID-19 symptoms. This is despite the fact that people with no symptoms can spread the virus (Fig. 8). As the USA has large fire camps where large groups of fire fighters are stationed together, the risk of infection spreading unknowingly is very high. Despite this, regular testing is not available and there is not sufficient personal protective equipment, as highlighted by a call for action by United States senators to the White House on 18 May 2020 (link). Survey respondents are concerned about the lack of preventive testing, as illustrated in Fig. 9. To keep people safe and ensure continuation of wildland fire management, frequent rapid COVID-19 testing is essential.
Can COVID-19 be caught from a person who has no symptoms?

COVID-19 is mainly spread through respiratory droplets expelled by someone who is coughing or has other symptoms such as fever or tiredness. Many people with COVID-19 experience only mild symptoms. This is particularly true in the early stages of the disease. It is possible to catch COVID-19 from someone who has just a mild cough and does not feel ill.

Some reports have indicated that people with no symptoms can transmit the virus. It is not yet known how often it happens. WHO is assessing ongoing research on the topic and will continue to share updated findings.

Figure 8 WHO information about COVID-19 spread (source)

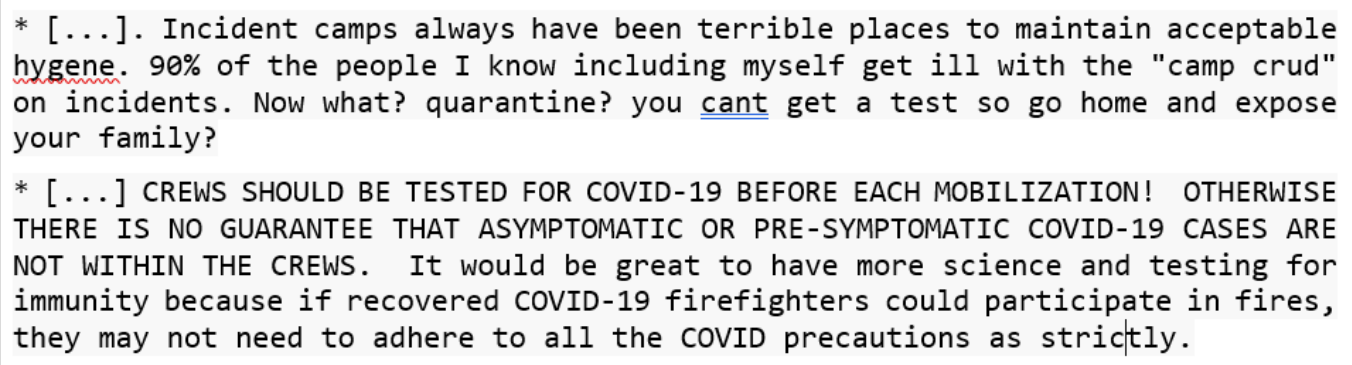
hygene. $90 \%$ of the people I know including myself get ill with the "camp crud" on incidents. Now what? quarantine? you cant get a test so go home and expose your family?

* [...] CREWS SHOULD BE TESTED FOR COVID-19 BEFORE EACH MOBILIZATION! OTHERWISE THERE IS NO GUARANTEE THAT ASYMPTOMATIC OR PRE-SYMPTOMATIC COVID-19 CASES ARE NOT WITHIN THE CREWS. It would be great to have more science and testing for immunity because if recovered COVID-19 firefighters could participate in fires, they may not need to adhere to all the COVID precautions as strictly.

Figure 9 Example of survey comments on COVID-19 testing

\section{Outlook to Brief 2}

We hope to publish the full analysis of the survey responses in Brief 2 mid June, which will be available from the Wageningen University library website here (this link is inactive until the report is available). This analysis will deal with all four sections of the survey, namely: 1) characterization of the respondent organization; 2) general fire management; 3 ) fire suppression (at operational level, incident command and specialized support staff, crew level, aerial means, fire strategies and tactics); and 4) fire training, risk reduction, readiness and recovery.

\section{Additional resources}

Below we include two opportunities for more information, presented in webinars. This is by far not a complete list. If you would like your activity or information material to be shared in our Briefs, please contact us via the contact information listed on the first page.

- 'COVID-19 and Wildfire webinar series', organized by Intterra and the Western Fire Chiefs Association (WFCA) in the USA, focusing on the issues and guidance circulating throughout the 
fire service. The series starts on Wednesday May 27 and participation is free but registration is required. More information can be found here. Language is expected to be English.

- 'O reflexo do COVID-19 no sistema de defesa da floresta contra incêndios em 2020', 2-hour webinar organized by the Centro de Estudos sobre Incêndios Florestais da ADAI (University of Coimbra, Portugal). The webinar was held on 12 May 2020, includes a wide multidisciplinary range of stakeholders across emergency and medical services, and can be viewed here. The language is Portuguese.

\section{References}

Moore, P., Hannah, B., de Vries, J., Poortvliet, M., Steffens, R., Stoof, C.R. (2020). Wildland Fire Management under COVID-19. Brief 1, Review of Materials. Wageningen University, The Netherlands. https://doi.org/10.18174/521344.

\section{Acknowledgements}

We thank all respondents for taking the time to complete the survey, so others can learn from experienced gained around the world. We are aware that preparation of fire management under COVID-19 is time consuming and very much appreciate your help. We also thank Steve Miller for sharing the interagency mobilization checklist (Fig. 5). 